\title{
Influence of growth hormone therapy on the occurrence of a second neoplasm in survivors of childhood cancer
}

\author{
Cécile Thomas-Teinturier (1D) 1,2,3, Isabelle Oliver-Petit ${ }^{4}$, Helene Pacquement ${ }^{5}$, Brice Fresneau ${ }^{1,2,6}$, \\ Rodrigue Sétchéou Allodji ${ }^{1,2,7}$, Cristina Veres ${ }^{1,2,7}$, Stephanie Bolle ${ }^{8}$, Delphine Berchery ${ }^{9}$, \\ Charlotte Demoor-Goldschmidt ${ }^{1,2,10}$, Nadia Haddy ${ }^{1,2,7}$, Ibrahima Diallo ${ }^{1,2,7}$ and Florent de Vathaire ${ }^{1,2,7}$
}

${ }^{1}$ Cancer and Radiation, CESP, Unit 1018 INSERM, Villejuif, France, ${ }^{2}$ University Paris-Saclay, Villejuif, France, ${ }^{3}$ Department of Pediatric Endocrinology, AP-HP, Université Paris Saclay, site Bicetre, Le Kremlin Bicêtre, France, ${ }^{4}$ Department of Pediatric Endocrinology, Children Hospital, Toulouse, France, ${ }^{5}$ Department of Pediatrics Oncology, Institut Curie, Paris, France, ${ }^{6}$ Department of Pediatrics Oncology, Institut Gustave Roussy, Villejuif, France, ${ }^{7}$ Department of Research Gustave Roussy, Villejuif, France, ${ }^{8}$ Department of Radiotherapy Oncology, Institut Gustave Roussy, Villejuif, France, ${ }^{9} \mathrm{Centre}$ Claudius Régaud, Toulouse, France, and ${ }^{10}$ Department of Pediatrics Oncology, CHU Angers, Angers, France

Correspondence

should be addressed

to $C$ Thomas-Teinturier

Email

cecile.teinturier@aphp.fr

\begin{abstract}
Context: Growth hormone (GH) deficiency is a common late effect of cranial irradiation. However, concerns have been raised that GH treatment might lead to an increased risk of a second neoplasm (SN).

Objective: To study the impact of GH treatment on the risk of SN in a French cohort of survivors of childhood cancer (CCS) treated before 1986.

Design and setting: Cohort study and nested case-control study.

Participants: Of the 2852 survivors, with a median follow-up of 26 years, 196 had received GH therapy (median delay from cancer diagnosis: 5.5 years).

Main outcome measures: Occurrence of SN

Results: In total, 374 survivors developed a SN, including 40 who had received GH therapy. In a multivariate analysis, GH treatment did not increase the risk of secondary non-meningioma brain tumors (RR: $0.6,95 \% \mathrm{Cl}: 0.2-1.5, P=0.3$ ), secondary non-brain cancer (RR: $0.7,95 \% \mathrm{Cl}: 0.4-1.2, P=0.2$ ), or meningioma (RR: 1.9, 95\% Cl: 0.9-4, $P=0.09$ ). Nevertheless, we observed a slight non-significant increase in the risk of meningioma with GH duration: 1.6-fold (95\% Cl: 1.2-3.0) after an exposure of less than 4 years vs 2.3 -fold $(95 \% \mathrm{Cl}: 0.9-5.6)$ after a longer exposure ( $P$ for trend $=0.07$ ) confirmed by the results of a case-control study.

Conclusion: This study confirms the overall safety of GH use in survivors of childhood cancer, which does not increase the risk of a SN. The slight excess in the risk of meningioma in patients with long-term GH treatment is non-significant and could be due to difficulties in adjustment on cranial radiation volume/dose and/or undiagnosed meningioma predisposing conditions.
\end{abstract}

\section{Introduction}

Growth hormone (GH) deficiency is a common endocrine sequela in children who received radiation therapy to the hypothalamus and/or pituitary gland

$(1,2,3,4,5)$. It leads to decelerating growth and needs GH therapy in order to achieve normal adult height. Hence, GH treatment is currently being used with the intention 
of improving adult height, metabolic state (muscle strength, lean body mass, lipid profiles), osteoporosis and quality of life in survivors of childhood cancer. As $\mathrm{GH}$ and IGF1 (insulin-growth factor 1) have mitogenic and pro-proliferative properties, there have been concerns that GH treatment might increase the risk of a second neoplasm (SN), either by itself or by interacting with radiotherapy and/or chemotherapy. These concerns have been fueled by a variety of clinical studies, in particular, the studies focusing on acromegaly, a condition of chronically increased GH levels, where an elevated colon cancer mortality rate (standardized mortality ratio, 2.47; 95\% CI: 1.31-4.22) has been reported (6). Data from epidemiological studies also support this, showing a higher risk of prostate or colorectal cancer occurrence when IGF1 serum level was in the higher quartile of the normal range in comparison with the lowest quartile $(7,8)$. But these situations differ from a GH substitutive therapy for GH deficiency where IGF1 levels are restored to normal but not high values.

Prior reports on the influence of GH therapy on SN occurrence in survivors of childhood cancer are scarce and come almost exclusively from the CCSS (Childhood Cancer Survivors Study) (9, 10, 11). An increased occurrence of overall $\mathrm{SN}$ in survivors exposed to $\mathrm{GH}$ therapy in comparison with those who were not exposed was reported with a relative risk of 3.2 (95\% CI: 1.9-5.5), but updated to 2.2 (95\% CI: 1.3-3.5) after a 32-month longer follow-up $(9,10)$ and to 1.0 (95\% CI: 0.6-1.8) in an analysis limited to secondary CNS tumors (11). The SN observed were mostly meningioma occurring in an irradiated location, with a median latency period of 12 years in the GH-exposed group compared to 19 years in the non-exposed group (10). An update of the same cohort focused on subsequent CNS tumors and found no increased overall risk associated with GH exposure after adjusting for the brain radiation dose (11). Other studies came from GH post-marketing studies but the lack of a control group and the relatively short follow-up make their findings questionable $(12,13)$.

The aim of this study was to assess the possible influence of $\mathrm{GH}$ treatment on the long-term risk of the occurrence of a SN in survivors of childhood solid cancer. As it has been suggested that the increased risk of $\mathrm{SN}$ in the GH treated group is lessened with a longer follow-up, and since the latency period observed for the occurrence of meningioma in survivors is around 20 years, our cohort of childhood cancer survivors that has the longest follow-up (median 26 years) seems to be appropriate to establish if GH treatment really is increasing the rate of SN or only reducing their time of onset.

\section{Subjects and methods}

A total of 3172 5-year survivors of a childhood solid malignancy from the Euro2K cohort (14) diagnosed before the age of 16, between 1 January 1945 and 31 December 1985, and treated in France, were included.

Detailed medical information was taken from the medical record of each patient. Data collected included primary tumor type, grouped according to a widely accepted classification system based principally on histology (15), all treatments for primary cancer, including cumulative doses of each chemotherapeutic agent expressed in milligrams per square meter, surgical procedures and quantitative data on radiation therapy fields and doses. A detailed description of the chemotherapy received by the cohort has been published elsewhere (14).

The cohort was followed by self-questionnaires (76\% response to first self-questionnaire), regular access to medical records of hospitals, as well as by linkage with the French National Hospital and Health Insurance database (SNIIR-AM).

The diagnoses of first cancer and SN (reported from medical records, self-report questionnaires or SNIIRAM) were histologically confirmed by getting copies of pathological records of all SN that have been biopsied.

In accordance with the French regulations, the protocol of the study was approved by a regional committee of ethics and by the national committee protecting the confidentiality of the Commission Nationale de l'Informatique et des Libertés (CNIL), and by the ethics committee of the National Institute of Medical Research and Health (INSERM). All patients have given their written consent prior to receiving the selfquestionnaire, and after full explanation of the purpose and nature of all procedures used.

\section{GH study}

From the 3172 French Euro2K patients, we excluded 308 patients born before 1958 because GH only became available in France in the 1970s.

We identified patients treated with GH using different tools. Seventy-six percent of long-term survivors answered a self-questionnaire in which a specific item addressing $\mathrm{GH}$ therapy has been ticked by 109 patients. Medical records 
examination evidenced that, of these 109 participants who declared having received growth hormone therapy, only 52 had really received such therapy. We also used a semiautomated medical record screening method with specific keywords 'growth', 'growth retardation', 'hormone', 'endocrine', 'deficiency', 'GH', 'endocrinology'. All medical records with these terms were then examined manually. Lastly, a systematic review of all medical records of patients having received an estimated radiation dose of 10 Gray (Gy) or more to the pituitary gland was performed. If insufficient information was available in the medical records of childhood cancer treatment centers, we checked the pediatric endocrinology department files where the patients might have been treated (Paris, Toulouse and Reims). In total, 756 medical records were thus reviewed. We were able to validate 196 patients who had received GH therapy. In 12 cases, the medical records did not allow the researchers to confirm or to exclude GH exposure and patients were lost to follow-up, so we decided to exclude them from analysis (for flow chart see Fig. 1).

\section{Radiation dosimetry}

Hospital physicists obtained radiotherapy and patient data from technical radiotherapy records for all included patients who received radiotherapy. For each of these patients, radiation treatment was reconstructed using a commercialized Treatment Planning System (TPS), Isogray®, in which patient images were replaced by anthropomorphic phantoms mimicking the anatomical dimensions of the patient in which the main organs of interest were contoured $(16,17,18,19)$. Details about the methods have been previously described (20).

For the purposes of the study, the meninges were defined as a $2 \mathrm{~mm}$ thick envelope around each lobe of the brain.

\section{Meningioma case-control study}

In order to take into account the radiation dose received by the meninges, we carried out a case-control study nested into the cohort.

Each of the 45 survivors, having developed a secondary meningioma, was matched with one to five controls according to the availability (in total 198 controls), using the following criteria: median radiation dose to the meninges divided into five groups (no radiotherapy, 0 to less than $1 \mathrm{~Gy}, 1$ to less than $20 \mathrm{~Gy}, 20$ to less than $30 \mathrm{~Gy}, 30 \mathrm{~Gy}$ or more), gender, age at first cancer diagnosis
( \pm 4 years), year of first cancer diagnosis $( \pm 4$ years) and follow-up duration (the control must have at least the same follow-up duration).

\section{Statistical analysis}

Descriptive analyses were done using the computer program SAS® Version 9.4. Univariate comparisons were performed using the Wilcoxon rank test. Univariate and multivariate analysis of the impact of GH on the incidence of SN were performed using a time-dependent Cox proportional hazard regression model (21).

Time to event was calculated from first cancer diagnosis to the date of the first occurrence of the following events: first $\mathrm{SN}$ diagnosis, end of follow-up or death. Only the first malignant SN and meningioma were considered, excluding non-melanoma skin cancer.

The cumulative incidence of SN was estimated using the Kaplan-Meier method and compared using a Logrank test. In order to take into account the very strong correlation between radiation dose distribution and GH treatment, and in addition to crude incidence curves (online), we added figures showing the adjusted cumulative incidence of second cancer according to GH exposure. For each outcome, the curves are the cumulative incidence adjusted on all significant risk factors, except GH (22). In these curves, the value of each covariable has been defined as being the observed mean of its distribution in the whole cohort.

In the cohort analysis, the association between exposure to $\mathrm{GH}$ and the relative risk (RR) for $\mathrm{SN}$ was analyzed taking into account the treatment modalities of cancer (radiation doses, number and type of drugs received, year of treatment), type of first cancer (brain tumor vs others), age at the diagnosis of cancer, gender and diagnosed predisposing factors such as neurofibromatosis. Kaplan-Meier curves of occurrence of the $\mathrm{SN}$ according to GH exposure were drawn. Ninetyfive percent CI were estimated using the maximum likelihood methods. All statistical tests were two-sided and a $P$-value of $<0.05$ was considered as statistically significant.

The case-control study was analyzed using a conditional logistic regression which was stratified on gender, age at first cancer diagnosis, year of first cancer diagnosis, follow-up duration and median radiation dose to the meninges, and was adjusted for the risk factors used in the cohort analysis and average radiation dose to the meninges of the lobe where meningioma occurred for 


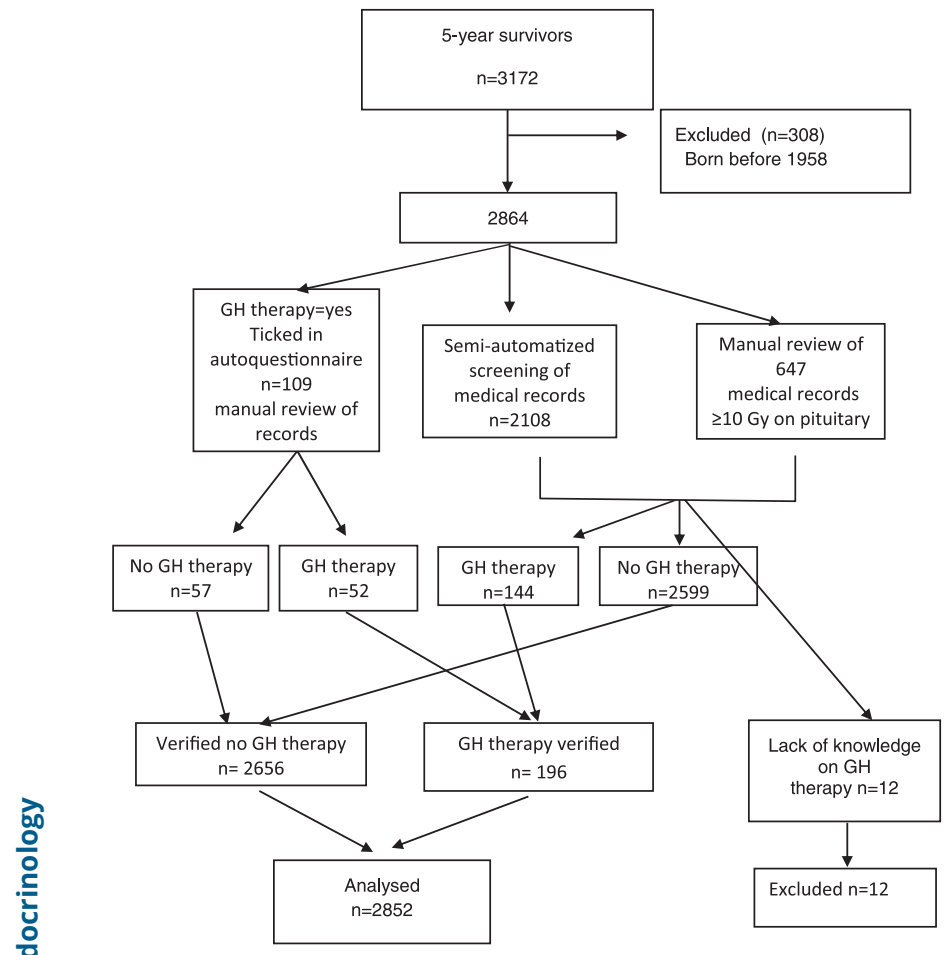

Figure 1

Flow chart depicting selection of patients from the Euro2K cohort.

the case or the corresponding meninges for the matched controls.

\section{Results}

Of the 2852 survivors born since 1958, with a median follow-up of 26 years (range 5-54), 196 had received GH therapy during childhood or adolescence. The clinical characteristics of survivors, according to GH exposure, are summarized in Table 1. Survivors were more likely to have received $\mathrm{GH}$ therapy when the first cancer diagnosis occurred after 1975 due to a better availability of GH after this period. In total, 126 (64.3\%) survivors who received $\mathrm{GH}$ had been treated for a brain tumor, 22 (11.2\%) for a retinoblastoma, $20(10.2 \%)$ for a lymphoma and 28 (14.3\%) for another type of tumor.

In $16 \%$ of survivors who received GH therapy, a predisposition to cancer was identified, this was mostly neurofibromatosis or genetic retinoblastoma vs only $4 \%$ of those who were not treated with GH.

The median delay between cancer diagnosis and GH therapy was 5.5 years (-2-22.5) and the median duration of GH therapy was 4 years (0.2-14.5). Half of the survivors had received only cadaveric $\mathrm{GH}$.

\section{Descriptive data on SN}

A total of 374 patients developed at least one SN, 40 of which following $\mathrm{GH}$ treatment.

In the GH-treated survivors, all SN were solid tumors, no secondary leukemia was found (Supplementary Table 1, see section on supplementary materials given at the end of this article). Two-thirds of the SN were brain neoplasms $(n=26), 17$ meningiomas (2 occurring in patients with Gorlin syndrome) and 9 glial tumors

Table 1 Patients characteristics according to GH therapy.

\begin{tabular}{|c|c|c|c|}
\hline Variables & $\boldsymbol{n}$ & GH treated & $\begin{array}{l}\text { Non-GH } \\
\text { treated }\end{array}$ \\
\hline$n$ & & 196 & 2656 \\
\hline Sex (male/female) & & $120 / 76$ & $1469 / 1187$ \\
\hline Age at cancer (years) & & $4(0$ to 13$)$ & $4(0$ to 18$)$ \\
\hline $\begin{array}{l}\text { Follow-up duration } \\
\text { (years)* }\end{array}$ & & $26(5$ to 41$)$ & 27 (5 to 54$)$ \\
\hline \multicolumn{4}{|l|}{ Cancer treatment period } \\
\hline Before 1970 & 393 & 5 & 388 \\
\hline 1970-1975 & 560 & 31 & 529 \\
\hline 1975-1980 & 800 & 67 & 733 \\
\hline 1980-1985 & 1099 & 93 & 1006 \\
\hline \multicolumn{4}{|l|}{ Cancer diagnosis $(n)$} \\
\hline Brain tumors & 400 & 126 & 274 \\
\hline Craniopharyngioma & 22 & 15 & 7 \\
\hline Medulloblastoma & 104 & 46 & 58 \\
\hline Germ cell tumors & 32 & 5 & 27 \\
\hline Glioma & 241 & 59 & 182 \\
\hline Meningioma & 1 & 1 & 0 \\
\hline Retinoblastoma & 136 & 22 & 114 \\
\hline Neuroblastoma & 416 & 9 & 407 \\
\hline Lymphoma & 502 & 20 & 482 \\
\hline Sarcoma & 523 & 16 & 507 \\
\hline Miscellaneous & 875 & 3 & 872 \\
\hline $\begin{array}{l}\text { Cancer predisposition, } \\
\text { total } n\end{array}$ & 129 & & \\
\hline Neurofibromatosis & 47 & 17 & 30 \\
\hline RB1 mutation & 41 & 10 & 31 \\
\hline Other & 41 & 4 & 37 \\
\hline \multicolumn{4}{|l|}{ GH therapy } \\
\hline $\begin{array}{l}\text { Age at start of GH } \\
\text { therapy (years) }\end{array}$ & & 10 (3 to 28$)$ & \\
\hline $\begin{array}{l}\text { Duration of GH } \\
\text { therapy (years) }\end{array}$ & & 4 (0.2 to 14.5$)$ & \\
\hline $\begin{array}{l}\text { Delay between cancer } \\
\text { diagnosis and } \mathrm{GH} \\
\text { therapy (years) }\end{array}$ & & $5.5(-2$ to 22.5$)$ & \\
\hline \multicolumn{4}{|l|}{ GH type $(n)$} \\
\hline Cadaveric only & & 97 & \\
\hline Recombinant only & & 78 & \\
\hline Both or unknown type & & 21 & \\
\hline
\end{tabular}


(4 occurring in patients with neurofibromatosis). Onethird of the SN were non-brain tumors, 9 sarcomas (2 occurring in patients with primary retinoblastoma), 1 melanoma, 2 thyroid carcinomas, 1 adenocarcinoma of the salivary gland 1 liver neuroepithelioma.

SN occurred with a median delay of 21 years (range: 3-35) in GH treated patients vs 26 years (range: 2-49) in untreated patients, but meningioma occurred with a median delay of 26 years (range: 3-41) in GH treated patients vs 25 years (range: 2-54) in untreated patients (Table 2). The crude incidence of overall SN was significantly higher in GH treated patients vs untreated patients $(P<0.0001)$ (Supplementary Fig. 1). This was mainly due to the fact that patients treated with $\mathrm{GH}$ were mostly survivors from a brain tumor and received higher radiation dose to the body and to the brain. When adjusting on type of childhood cancer and on all significant treatment factors (Table 3) the adjusted incidence of $\mathrm{SN}$ did not remain significantly higher in patients who received GH than in those who did not (Fig. 2). Similarly, the crude incidence of non-meningioma brain tumors and of meningioma was higher in patients who had been treated with $\mathrm{GH}$ than in those who had not $(P<0.0001)$, but this difference disappeared when adjusting on radiation dose distribution and other confounding factors (Fig. 2 and Table 3).

As patients who received GH therapy were not similar to those who did not, in terms of brain radiation dose, we studied the 955 survivors who had been exposed to at least
1 Gy on $10 \%$ of the brain's volume. Nevertheless, even within this selection, patients treated with GH therapy received a higher mean brain and pituitary radiation dose $(P<0.0001)$.

However, survivors with an endocrine follow-up for GH deficiency could have been subject to more frequent systematic MRI during follow-up leading to the overestimation of diagnosis of meningioma in $\mathrm{GH}$ deficient survivors. We reviewed the clinical records of 40 out of 43 patients who developed a meningioma to check if meningioma was diagnosed on a systematic MRI or through clinical symptoms (unavailable data for 3). In 30/40 patients, the diagnosis was made on clinical symptoms (headache, neurologic impairment, etc.) and in $10 / 40$ patients on systematic neuroimaging, with no difference in the GH-treated group (25\%) vs non-GHtreated survivors (25\%).

\section{Multivariate analysis}

In a multivariate analysis, GH treatment was not associated with a significant increase in SN risk (RR: 1.3, 95\% CI: $0.9-2, P=0.2$ ), nor in meningioma occurrence (RR: 1.9, 95\% CI: $0.9-4, P=0.09$ ) (Table 3). A statistically nonsignificant trend for a higher risk for meningioma with longer duration of $\mathrm{GH}$ therapy ( $>4$ years) was observed (RR: 2.3 (95\% CI: 0.9-5.6) $P=0.07$ ) (Table 4). A younger age at cancer diagnosis, being female, radiotherapy, the number of chemotherapy drugs and neurofibromatosis

Table 2 Frequency and characteristics of second neoplasms (SN) according to GH exposure. Data are presented as $n(\%)$, unless otherwise stated.

\begin{tabular}{l}
\hline Variables \\
\hline$n(\%)$ \\
Age at cancer* (years) \\
Age at SN* (years) \\
Delay to SN* (years) \\
Neurofibromatosis (SN/total) \\
According to first cancer diagnosis (SN/exposed) \\
Brain tumor \\
Lymphoma \\
Retinoblastoma \\
Sarcoma \\
Others \\
According to cancer treatment exposure (SN/exposed) \\
Radiotherapy \\
Chemotherapy \\
SN type \\
Non-brain SN \\
Brain SN** \\
meningioma \\
* Median (range); **other than meningioma.
\end{tabular}

\begin{tabular}{c}
\hline SN after GH exposure \\
\hline $40 / 196(20.4 \%)$ \\
$3.5(0-11)$ \\
$26.5(6-42)$ \\
$22(3-35)$ \\
$7 / 17(41.2 \%)$ \\
$28 / 126(22.2 \%)$ \\
$4 / 20(20 \%)$ \\
$2 / 22(9 \%)$ \\
$4 / 16(25 \%)$ \\
$2 / 12(16.7 \%)$ \\
$40 / 192(20.8 \%)$ \\
$25 / 122(20.5 \%)$ \\
$14 / 40(35 \%)$ \\
$9 / 40(22.5 \%)$ \\
$17 / 40(42.5 \%)$
\end{tabular}

\begin{tabular}{ccc}
\cline { 1 - 1 } SN no GH exposure & & $\boldsymbol{P}$ \\
\cline { 1 - 1 } $334 / 2656(12.6 \%)$ & & \\
$5(0-18)$ & & $<0.0001$ \\
$33.5(4-54)$ & & 0.01 \\
$27(2-49)$ & & 0.006 \\
$11 / 30(36.7 \%)$ & & 0.8 \\
& & 0.01 \\
$33 / 274(12 \%)$ & & 0.5 \\
$76 / 482(15.8 \%)$ & & 0.7 \\
$16 / 114(14 \%)$ & & 0.2 \\
$66 / 507(13.2 \%)$ & & 0.6 \\
$143 / 1279(11.2 \%)$ & & 0.1 \\
& & 0.04 \\
$286 / 1746(16.4 \%)$ & & 0.0001 \\
$279 / 2082(13.4 \%)$ & & 0.001 \\
& & \\
$287 / 334(86 \%)$ & & \\
$20 / 334(6 \%)$ &
\end{tabular}


were associated with a higher risk of SN. Methotrexate use was not associated with an increased risk of meningioma, neither in the yes or no analysis, nor in the cumulative dose, nor in intrathecal administration. Mechlorethamine was associated with a 14-fold higher risk of meningioma (95\% CI: 3.8-50, $P<0.0001$ ), but only 19 patients have been exposed to mechlorethamine, out of them 6 had meningioma. Estrogen/progestin use was not associated with an excess risk of meningioma in women.

After exclusion of patients with neurofibromatosis, results remained relatively unchanged in terms of relative risk except for the risk of meningioma that became weakly significant. These results should be treated with caution because the risk is weak $(\mathrm{RR}=2.0$, 95\% CI: $1.1-$ 3.9, $P=0.04$ ) and there were no significant interaction between neurofibromatosis and growth hormone therapy on the occurrence of $\mathrm{SN}$, so a subgroup analysis was not justified.

\section{Case-control study on the risk of meningioma}

The duration of GH treatment was associated with a trend of increasing the risk of secondary meningioma with a longer duration, at the limit of statistical significance (RR: 2.96, 95\% CI: 099-8.86, $P=0.05$ ) (Table 5).

\section{Discussion}

This study is of strong importance because of the large cohort with clinically validated outcomes, the estimation of the dose distribution in the meninges available for all survivors and data on the duration of GH therapy. While data are mostly confirmatory in nature, it is a unique study that adds valuable clinical details to the previously published studies, for instance, regarding the circumstances under which meningiomas were detected. Because meningioma may remain asymptomatic over a long period of time, the possibility of a surveillance bias in survivors treated with $\mathrm{GH}$ has been reported in previous studies $(9,10)$. To address this point, we were able to study the clinical records of 40 patients who had developed a meningioma. There was no difference in the percentage of systematic MRI leading to the diagnosis in the GH-treated vs non-GH-treated survivors. So, this assumption was not confirmed in our cohort.

The data from this study suggest that GH therapy is not associated with an increased risk of developing a second tumor, except a meningioma, in this cohort of survivors of solid cancer. In particular, we observed no 
cases of secondary leukemia and no increased occurrence of non-brain tumors, in particular, osteosarcomas. This is reassuring for all pediatric cancer survivors who will need GH therapy for GH deficiency after cranial radiation therapy.

Survivors of childhood cancer exposed to radiation therapy have a high risk of developing a subsequent radiation-induced second neoplasm. Radiation dose confounds the relationship between $\mathrm{GH}$ and the occurrence of a second CNS neoplasm, as higher doses are associated with a higher likelihood of GH deficiency (5) and an increased risk of SN $(23,24)$. Moreover, underlying inherited predisposition to cancer, in particular, neurofibromatosis, Gorlin syndrome, genetic retinoblastoma or Li-Fraumeni syndrome may lead to an increased frequency of SN that could bias the results. When adjusting for some of these confounding risk factors, the role of GH in the risk of $\mathrm{SN}$ was not apparent for non-meningioma SN.

Concerning the risk of meningioma, prior research in CCSS has shown conflicting results raising the hypothesis that meningioma occurred earlier or was detected earlier in GH-treated survivors $(9,10)$. In that cohort, the latency period for developing a meningioma in the GH-treated group was 12.2 years compared to 19 years in the non-GHtreated survivors (10). Our study, with a longer follow-up, does not confirm this observation. The results from their last study on the same cohort are even more surprising. With a longer follow-up (published 7 years after), they found that the meningioma rate was increased two-fold
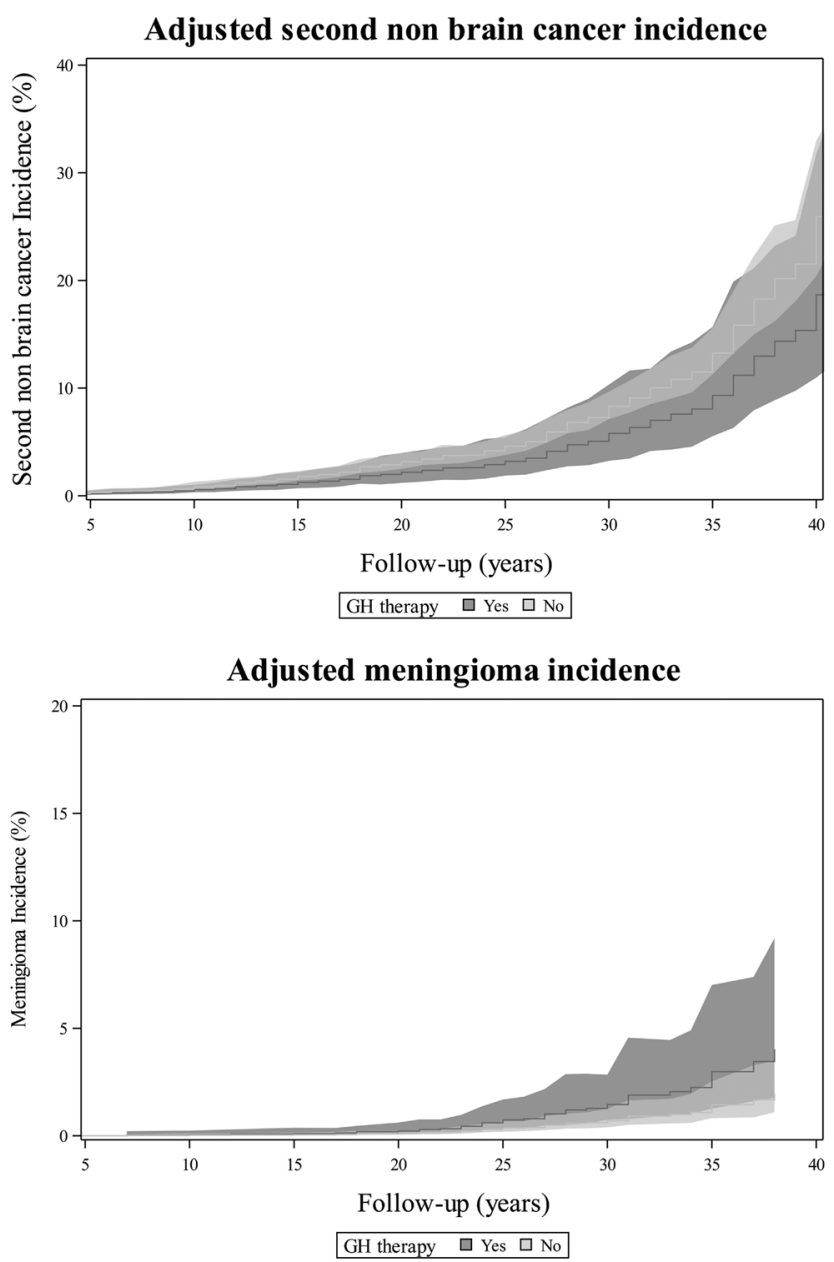

\section{Figure 2}

Adjusted cumulative incidence of second cancer depending on follow-up duration in years, stratified by GH treatment. For each outcome, the curves are the cumulative incidence adjusted for all the significant risk factors of table 3, except GH. The value of each covariable has been defined as the observed mean of its distribution in the whole cohort. Dark gray area represents survivors who received GH therapy and light gray area represents those who did not, with $95 \% \mathrm{Cl}$. 


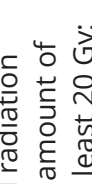

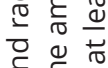

它兵

थे

บ $\frac{1}{2}$

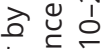

ญั ত

先 $\frac{\sqrt{0}}{\frac{1}{1}}$

는

m

ㅇํㅇ 잉

ลิธิว

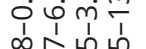

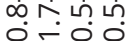
อ ¿ ơm

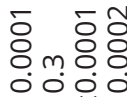
능

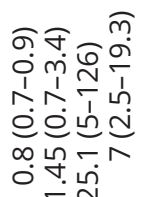

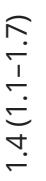

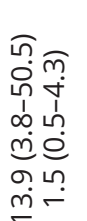

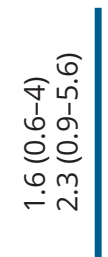
$\stackrel{n}{\circ}$

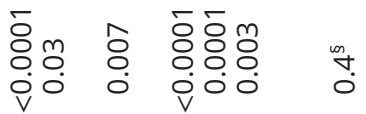
อิก ז่ อं ナั ๑ฺุ กิ ๓๐ล 10.

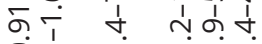
$\dot{0}=$ Е ஜ̣m 응ㅇㅇㅇㅇㅇㅇ응 จं 융융

$\stackrel{\infty}{\dddot{O}}$ ซิ ㄷำ อீ ษ่ คด เก ดิธล์ ำ ติโ

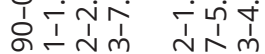

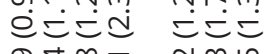
ஜุণ

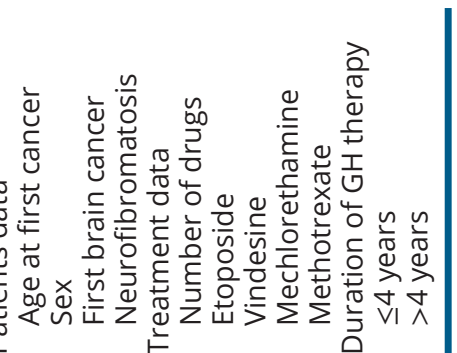

Table 5 Case-control study: variation in RR of meningioma according to $\mathrm{GH}$ duration and gender.

\begin{tabular}{|c|c|c|c|c|}
\hline \multirow{2}{*}{$\begin{array}{l}\text { GH therapy } \\
\text { duration }\end{array}$} & \multirow[b]{2}{*}{ Cases } & \multirow[b]{2}{*}{ Controls } & \multicolumn{2}{|l|}{ Relative risk* } \\
\hline & & & RR $(95 \% \mathrm{Cl})$ & $P^{\star \star}$ \\
\hline All & & & & 0.05 \\
\hline No & 28 & 140 & 1 & \\
\hline$\leq 4$ years & 7 & 28 & $1.87(0.61-5.74)$ & \\
\hline$>4$ years & 10 & 30 & $2.96(0.99-8.86)$ & \\
\hline Men & & & & 0.1 \\
\hline No & 11 & 48 & 1 & \\
\hline$\leq 4$ years & 1 & 10 & $0.57(0.03-10.4)$ & \\
\hline$>4$ years & 5 & 16 & $4.09(0.37-45.6)$ & \\
\hline Women & & & & 0.07 \\
\hline No & 17 & 92 & 1 & \\
\hline$\leq 4$ years & 6 & 18 & $2.48(0.68-9.06)$ & \\
\hline$>4$ years & 5 & 14 & $2.90(0.74-11.35)$ & \\
\hline
\end{tabular}

*Adjusted on radiation dose to the location of meningioma, methotrexate, mechlorethamine and number of drugs exposure; **trend test.

in non-GH-treated group (138 cases (1.2\%) vs $62(0.05 \%))$, but it remained almost the same in the GH-treated group (10 (3\%) vs $9(2.5 \%))$ (11). No hypothesis was clearly mentioned to explain this difference in meningioma occurrence in the two groups. They found no increase in the risk of occurrence of a subsequent meningioma in survivors who have been treated with GH, but they did not study the duration of GH therapy, nor the age of the patients when they received GH therapy. A younger age at cancer diagnosis, being female, and a higher cranial radiation dose were associated with increased rates of meningioma, as in our study.

In our study, in a multivariate analysis, GH treatment was associated with a two- to three-fold non-significant increased risk of meningioma and the study on the effect of the duration of GH therapy could be considered as supporting this slight excess risk even if statistically nonsignificant after adjustment for radiation dose. However, GH-treated survivors had received a higher radiation dose to the meninges, especially doses above $30 \mathrm{~Gy}$. Yet, Taylor reported that the risk of meningioma is strongly and linearly related to radiation dose (568-fold higher risk for dose more than 30 gray) (24). Therefore, this extreme excess risk of meningioma associated with radiation dose higher than 30 Gy received by many GH-treated survivors could explain their slightly statistically nonsignificant excess risk of developing a meningioma. In addition, longer duration of GH therapy was associated with a younger age at cancer diagnosis. Younger age at cancer diagnosis could be associated with a higher rate of undiagnosed genetic meningioma predisposition, such as Gorlin syndrome. 
Due to the small number of events and the number of cofactors influencing the risk of meningioma that was associated in patients who received GH therapy (such as higher cranial radiation dose, younger age at cancer diagnosis and cancer predisposition), it could be anticipated that adjustment in the multivariate analysis is imprecise. Taken together, our conclusion would be that there is no evidence that GH treatment itself is responsible for the remaining non-significant excess of risk of meningioma.

We thought that a case-control study could suppress this bias but even if we matched cases and controls on the median radiation dose to the meninges and adjusted the model for the radiation dose at the location of meningioma, there was still a slight excess risk of meningioma in GH-treated survivors. Nevertheless, the number of events is small, the CIs are wide and at the limit of significance and this RR is weak compared to that of radiation dose.

A recent meta-analysis has shown that GH therapy does not appear to increase the risk of developing $\mathrm{SN}$ and is beneficial for improving the final height, lipid profiles and quality of life in survivors of childhood cancer (25).

\section{Limitations}

The small numbers of meningioma may have led to a lack of strength to detect a significant association. As this is a retrospective cohort study, residual confounding is a possibility, in particular undiagnosed predisposing factors for meningioma. We could not evaluate the role of $\mathrm{GH}$ dose, IGF-1 concentration during GH treatment and the use of cadaveric vs recombinant GH. Lastly, these data may not be applicable to the new techniques of radiation therapy.

\section{Conclusion}

This study confirms the safety of GH use in survivors of childhood cancer with no significant influence on the secondary tumor. Even if we observed a slight statistically non-significant occurrence of two- to three-fold excess risk of meningioma in GH-treated survivors, there is no clear evidence that GH treatment itself is responsible for this excess of risk. Moreover, this risk is weak compared to the extreme risk associated with high doses of cranial radiation received by these patients. A life-long follow-up using MRI is mandatory after childhood brain radiation therapy in order to detect secondary meningioma.

\section{Supplementary materials}

This is linked to the online version of the paper at https://doi.org/10.1530/ EJE-20-0369.

\section{Declaration of interest}

This study was completely independent of any pharmaceutical company or other commercial interest. C T T and I O P have received travel grants to attend meetings and speaker fees for scientific conferences from drug companies (Merck-Serono, Ipsen, Sandoz, Lilly, and Novo-Nordisk). The other authors declare that they have no conflicts of interest.

\section{Funding}

This work was supported by grants from EDF and from the Fondation ARC (Program PopHARC). This research used the Euro2K cohort, a resource supported by the Société Française des Cancers de I'Enfant, the Ligue Nationale Contre le Cancer (LNCC), the Institut de Recherche en Santé Publique (IRESP), Agence Nationale pour la Recherche (Projet Hope-Epi), and the Fondation Pfizer for the childhood and adolescent health. The funding agencies had no role in the design and conduct of the study; nor in the collection, management, analysis and interpretation of the data; nor in the preparation, review, and approval of the manuscript.

\section{Author contribution statement}

C T T and F D V had full access to the data and take responsibility for the integrity of the data and the accuracy of the data analysis. C T T and F D V were involved in the study concept and design. I O P, B F, H P, R S A, M M, I D, C V, and N H contributed todata collection. C T T, I O P, I D, C V, and $\mathrm{N} \mathrm{H}$ validated the data. C T T, F D V, and I D were involved in the analysis and interpretation of the data. C T T was involved in manuscript writing. I O P, C D G, I D, S B, D B, and F D V critically reviewed the manuscript for important intellectual content. C T T and F D V were involved in the statistical analysis. C T T and F D V obtained funding.

\section{References}

1 Constine LS, Woolf PD, Cann D, Mick G, McCormick K, Raubertas RF \& Rubin P. Hypothalamic-pituitary dysfunction after radiation for brain tumors. New England Journal of Medicine 1993328 87-94. (https://doi.org/10.1056/NEJM199301143280203)

2 Sklar CA \& Constine LS. Chronic neuroendocrinological sequelae of radiation therapy. International Journal of Radiation Oncology, Biology, Physics 199531 1113-1121. (https://doi.org/10.1016/03603016(94)00427-M)

3 Hudson MM, Ness KK, Gurney JG, Mulrooney DA, Chemaitilly W, Krull KR, Green DM, Armstrong GT, Nottage KA, Jones KE et al. Clinical ascertainment of health outcomes among adults treated for childhood cancer. JAMA 2013309 2371-2381. (https://doi. org/10.1001/jama.2013.6296)

4 Brauner R, Rappaport R, Prevot C, Czernichow P, Zucker JM, Bataini P, Lemerle J, Sarrazin D \& Guyda HJ. A prospective study of the development of growth hormone deficiency in children given cranial irradiation, and its relation to statural growth. Journal of Clinical Endocrinology and Metabolism 198968 346-351. (https://doi. org/10.1210/jcem-68-2-346)

5 Clayton PE \& Shalet SM. Dose dependency of time of onset of radiation-induced growth hormone deficiency. Journal of Pediatrics 1991118 226-228. (https://doi.org/10.1016/s0022-3476(05)80487-1) 
6 Orme SM, Menally RJQ, Cartwright RA \& Belchetz PE. Mortality and cancer incidence in acromegaly: a retrospective cohort study. United Kingdom Acromegaly Study Group. Journal of Clinical Endocrinology and Metabolism 199883 2730-2734. (https://doi.org/10.1210/ jcem.83.8.5007)

7 Chan JM, Stampfer MJ, Giovannucci E, Gann PH, Ma J, Wilkinson P, Hennekens CH \& Pollak M. Plasma insulin-like growth factor 1 and prostate cancer risk: a prospective study. Science 1998279 563-566. (https://doi.org/10.1126/science.279.5350.563)

8 Zhang R, Xu GL, Li Y, He LJ, Chen LM, Wang GB, Lin SY, Luo GY, Gao XY \& Shan HB. The role of insulin-like growth factor 1 and its receptor in the formation and development of colorectal carcinoma. Journal of International Medical Research 201341 1228-1235. (https:// doi.org/10.1177/0300060513487631)

9 Sklar CA, Mertens AC, Mitby P, Occhiogrosso G, Qin J, Heller G, Yasui $\mathrm{Y} \&$ Robison LL. Risk of disease recurrence and second neoplasms in survivors of childhood cancer treated with growth hormone: a report from the childhood cancer survivor study. Journal of Clinical Endocrinology and Metabolism 200287 3136-3141. (https:// doi.org/10.1210/jcem.87.7.8606)

10 Ergun-Longmire B, Mertens AC, Mitby P, Qin J, Heller G, Shi W, Yasui Y, Robison LL \& Sklar CA. Growth hormone treatment and risk of second neoplasms in the childhood cancer survivor. Journal of Clinical Endocrinology and Metabolism 200691 3494-3498. (https:// doi.org/10.1210/jc.2006-0656)

11 Patterson BC, Chen Y, Sklar CA, Neglia J, Yasui Y, Mertens A, Armstrong GT, Meadows A, Stovall M, Robison LL et al. Growth hormone exposure as a risk factor for the development of subsequent neoplasms of the central nervous system: a report from the Childhood Cancer Survivor Study. Journal of Clinical Endocrinology and Metabolism 201499 2030-2037. (https://doi.org/10.1210/jc.2013-4159)

12 Bell J, Parker KL, Swinford RD, Hoffman AR, Maneatis T \& Lippe B. Long term safety of recombinant human growth hormone in children. Journal of Clinical Endocrinology and Metabolism 201095 167-177. (https://doi.org/10.1210/jc.2009-0178)

13 Woodmansee WW, Zimmermann AG, Child CJ, Rong Q, Erfuth EM, Beck-Peccoz P, Blum WF, Robison LL \& GeNeSIS and HypoCCS International Advisory Boards. Incidence of second neoplasm in childhood cancer survivors treated with GH: an analysis of GeNeSIS and HypoCCS. European Journal of Endocrinology 2013168 565-573. (https://doi.org/10.1530/EJE-12-0967)

14 De Vathaire F, Hawkins M, Cambell S, Oberlin O, Raquin MA, Schlienger JY, Shamsaldin A, Diallo I, Bell J, Grimaud E et al. Second malignant neoplasms after a first cancer in childhood: temporal pattern of risk according to type of treatment. British Journal of Cancer 199979 1884-1893. (https://doi.org/10.1038/sj.bjc.6690300)

15 Birch JM \& Marsden HB. A classification scheme for childhood cancer. International Journal of Cancer 198740 620-624. (https://doi. org/10.1002/ijc.2910400508)
16 Alziar I, Bonniaud G, Couanet D, Ruaud JB, Vicente C, Giordana G, Ben-Harrath O, Diaz JC, Grandjean P, Kafrouni H et al. Individual radiation therapy patient whole-body phantoms for peripheral dose evaluations: method and specific software. Physics in Medicine and Biology 200954 N375-N383. (https://doi.org/10.1088/00319155/54/17/N01)

17 Bezin JV, Veres A, Lefkopoulos D, Chavaudra J, Deutsch E, de Vathaire F \& Diallo I. Field size dependent mapping of medical linear accelerator radiation leakage. Physics in Medicine and Biology 201560 2103-2106. (https://doi.org/10.1088/00319155/60/5/2103)

18 Alabdoaburas MM, Mege JP, Chavaudra J, Bezin JV, Veres A, de Vathaire F, Lefkopoulos D \& Diallo I. Experimental assessment of out-of-field dose components in high energy electron beams used in external beam radiotherapy. Journal of Applied Clinical Medical Physics 201516 435-448. (https://doi.org/10.1120/jacmp.v16i6.5616)

19 Benadjaoud MA, Bezin J, Veres A, Lefkopoulos D, Chavaudra J, Bridier A, de Vathaire F \& Diallo I. A multi-plane source model for out-of-field head scatter dose calculations in external beam photon therapy. Physics in Medicine and Biology 201257 7725-7739. (https:// doi.org/10.1088/0031-9155/57/22/7725)

20 Veres C, Allodji RS, Llanas D, Vu Bezin J, Chavaudra J, Mege JP, Lefkopoulos D, Quiniou E, Deutsh E, de Vathaire F et al. Retrospective reconstructions of active bone marrow dose-volume histograms. International Journal of Radiation Oncology, Biology, Physics 201490 1216-1224. (https://doi.org/10.1016/j.ijrobp.2014.08.335)

21 Cox DR. Regression models and life tables. Journal of the Royal Statistical Society: Series B 197234 187-202. (https://doi. org/10.1111/j.2517-6161.1972.tb00899.x)

22 Zhang X, Loberiza FR, Klein JP \& Zhang MJ. A SAS macro for estimation of direct adjusted survival curves based on a stratified Cox regression model. Computer Methods and Programs in Biomedicine 2007 88 95-101. (https://doi.org/10.1016/j.cmpb.2007.07.010)

23 Guerin S, Guibout C, Shamsaldin A, Dondon MG, Diallo I, Hawkins M, Oberlin O, Hartmann O, Michon J, Le Deley MC et al. Concomitant chemo-radiotherapy and local dose of radiation as risk factors for second malignant neoplasms after solid cancer in childhood: a case-control study. International Journal of Cancer 2007 120 96-102. (https://doi.org/10.1002/ijc.22197)

24 Taylor AJ, Little MP, Winter DL, Sugden E, Ellison DW, Stiller CA, Stovall M, Frobisher C, Lancashire ER, Reulen RC et al. Populationbased risks of CNS tumors in survivors of childhood cancer: the British childhood cancer survivor study. Journal of Clinical Oncology 201028 5287-5293. (https://doi.org/10.1200/JCO.2009.27.0090)

25 Tamhane S, Sfeir JG, Kittah NEN, Jasim S, Chemaitilly W, Cohen LE \& Murad MH. GH therapy in childhood cancer survivors: a systematic review and meta-analysis. Journal of Clinical Endocrinology and Metabolism 2018103 2794-2801. (https://doi.org/10.1210/ jc.2018-01205)

Received 19 April 2020

Revised version received 10 July 2020

Accepted 29 July 2020 